\title{
Slotted Printed Monopole UWB Antennas with Tunable Rejection Bands for WLAN/WiMAX and X-Band Coexistence
}

\author{
Issa ELFERGANI ${ }^{1}$, Jonathan RODRIGUEZ ${ }^{1,2}$, Ifiok OTUNG ${ }^{2}$, \\ Widad MSHWAT ${ }^{3}$, Read ABD-ALHAMEED ${ }^{3}$ \\ ${ }^{1}$ Instituto de Telecomunicações, Aveiro, Portugal \\ ${ }^{2}$ University of South Wales, Pontypridd, CF37 1DL UK \\ ${ }^{3}$ School of Engineering and Informatics, University of Bradford, Bradford, BD7 1DP, UK
}

\{i.t.e.elfergani, jonathan\}@av.it.pt, jonathan.rodriguez@southwales.ac.uk, \{w.f.a.amshwat, r.a.a.abd\}@bradford.ac.uk

Submitted September 25, 2017 / Accepted March 12, 2018

\begin{abstract}
Four versions of the compact hexagonal-shaped monopole printed antennas for UWB applications are presented. The first proposed antenna has an impedance bandwidth of $127.48 \%$ (3.1 GHz to $14 \mathrm{GHz})$, which satisfies the bandwidth for ultra-wideband communication systems. To reduce the foreseen co-channel interference with WLAN $(5.2 \mathrm{GHz})$ and $X$-Band systems $(10 \mathrm{GHz})$, the second and third antennas type were generated by embedding hexagonal slot on the top of the radiating patch. The integration of the half and full hexagonal slots created notched bands that potentially filtered out the sources of interference, but were static in nature. Therefore, a fourth antenna type with tunable-notched bands was designed by adding a varactor diode at an appropriate location within the slot. The fourth antenna type is a dual-notch that was electronically and simultaneously tuned from $3.2 \mathrm{GHz}$ to $5.1 \mathrm{GHz}$ and from $7.25 \mathrm{GHz}$ up to $9.9 \mathrm{GHz}$ by varying the bias voltages across the varactor. The prototypes of the four antenna versions were successfully fabricated and tested. The measured results have good agreement with the simulated results.
\end{abstract}

\section{Keywords}

Monopole printed antenna, UWB, notched bands, varactor

\section{Introduction}

UWB technology has several advantages such as high data rate, low power consumption, simple hardware configuration in practical applications and good resistance for multipath [1], [2]. At the heart of any UWB system, there is the UWB antenna that is designed to cover the frequency range of 3.1-10.6 GHz, as designated by the FCC (Federal Communication Commission) [3]. Moreover, the UWB antenna has to achieve several requirements such as high and stable gain, omnidirectional radiation pattern, wide impedance matching over the whole frequency band, low cost and compact size. Printed antennas, which are small in size, have low profiles, and provide ease of integration with hand-held terminals, have attracted much attention in recent years for UWB communication applications [4-10].

In the designated UWB operating band for the abovementioned antennas [4-10], there are several narrowband wireless systems within the workable bands below $10 \mathrm{GHz}$, such as the wireless local area network (WLAN) for IEEE802.11a operating at $5.15-5.825 \mathrm{GHz}$ band, IEEE 802.16 WiMAX system operating at 3.3-3.7 GHz, C-band $(4.4 \mathrm{GHz}-5.0 \mathrm{GHz})$, and X-band operating between 7.725 and $8.275 \mathrm{GHz}$ for ITU applications, which might potentially cause severe electromagnetic interference to UWB systems. To mitigate or avoid such potential interferences from these undesired narrowband signals, band-suppression features are required. Over the last 5 years, numerous techniques were applied in order to create the rejected bands on such type of antennas. The most common approaches were the stop-band feature developed in [11-21], whilst the [11-15] were designed with only a single notched band, that are not suitable for multi-notch band communication applications. Therefore, the design of an UWB antenna with dual band notch characteristics is becoming a very challenging task. To meet this challenge, various design techniques have been implemented to accomplish dual notch-band characteristic within the UWB range [16-21].

However, the frequency of most notched-band UWB antennas [11-21] are uncontrollable after their fabrications, which fail to meet the needs of reconfigurable notchedbands in real-time. Thus, the reconfigurable technique has received significant attention in the field of wireless communications. A number of reconfigurable notched-band UWB antennas have been discussed, the notched-band frequency can be continuously tuned with the aid of varactor diode or/and discretely switched by using PIN diode [22-29]. 
In summary, it is found that most of the antennas in [11-21] only provide either UWB designs with fixed single band suppression as in [11-15], or with dual notched features as in [16-21]. It should be noted, that the antenna designs in $[11-14,16-20]$ operate in the UWB spectrum, except at WiMAX and WLAN systems, where the notched bands were created. However, there is still a wide frequency spectrum from $6 \mathrm{GHz}$ to $11 \mathrm{GHz}$, in which those UWB antenna designs may share part of this frequency spectrum with adjacent spectral systems leading to interference at several applications and communication systems such as radar, space and satellite. Thus, designs in [15], [21] were proposed to avoid the envisaged interference that may take place around the X-band spectrum. However, all the proposed structures in [11-21] have fixed single/dual rejected bands, which cannot be altered/modified once these designs are fabricated. Therefore, it is required to design an UWB antenna with reconfigurable notch characteristics.

Tunability or frequency-agility of such rejected bands can pave the way towards mitigating this limitation. Findings in [22-29] have reported several UWB antennas with single or dual tunable-notched bands using varactor and PIN technologies. However, these antennas still do not have a filtering feature around the higher-band UWB spectrum $(6 \mathrm{GHz}$ to $11 \mathrm{GHz})$. To address all the above-mentioned limitations, this article presents a compact printed monopole UWB antenna with dual tunable rejected band technology: the initial notched band can be tuned from $3.2 \mathrm{GHz}$ to $5.1 \mathrm{GHz}$, whilst the second one is designed to be tuned from $7.25 \mathrm{GHz}$ to $9.9 \mathrm{GHz}$.

\section{Antenna Design and Procedure}

The full configurations of the proposed antennas are depicted in Fig. 1. The proposed designs are a type of printed monopole that operates over the UWB spectrum. The initial antenna consists of a hexagonal patch structure with a small stub along the feeding strip and a truncated ground plane, as shown in Fig. 1(a). The present antennas structures are built with the aid of using the CST EM simulator [30]. All the proposed designs are printed over a FR-4 substrate with a $0.8 \mathrm{~mm}$ thickness and relative permittivity of $\varepsilon=4.4$. After several optimization procedures, the final and optimal antenna design was accomplished, that occupies a compact area of $30 \times 30 \times 0.8 \mathrm{~mm}^{3}$. All the antenna versions are fed by a $50-\mathrm{Ohm}$ microstrip line. As can be seen in Fig. 1(e), the ground plane of the antenna was truncated and is printed on the other side of the substrate. The trapezoidal ground plane is virtually shared by both the radiator and feeding strip. A stub is printed over the strip to form a feed stub of appropriate shape as shown in Fig. 1(a), this significantly contributed towards improving the bandwidth. An optimum impedance bandwidth was achieved by the placing the stub over the strip line.

To further investigate the influence of the ground plane shape and the stub on the antenna bandwidth, the reflection coefficient of the antenna was simulated for the full

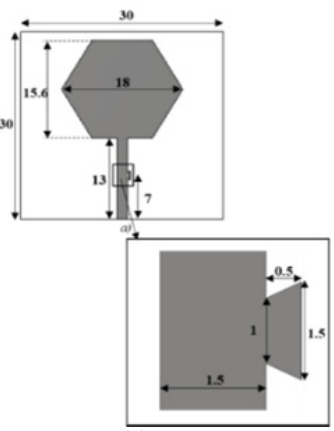

(a)

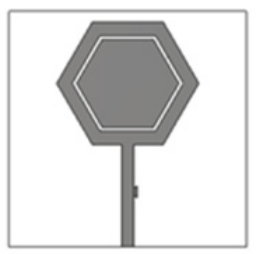

(c)

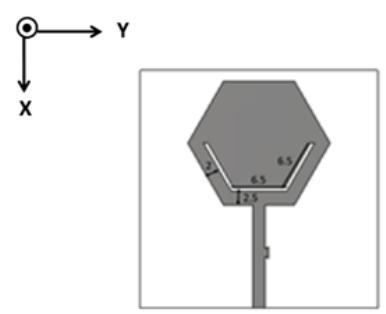

(b)

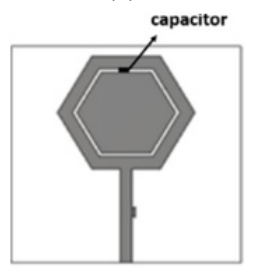

(d)

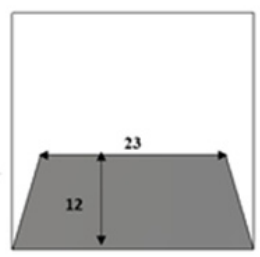

(e)

Fig. 1. The proposed antennas: (a) without slot, (b) with half hexagon slot, (c) with full hexagon slot, (d) with loaded capacitor,(e) ground plane.

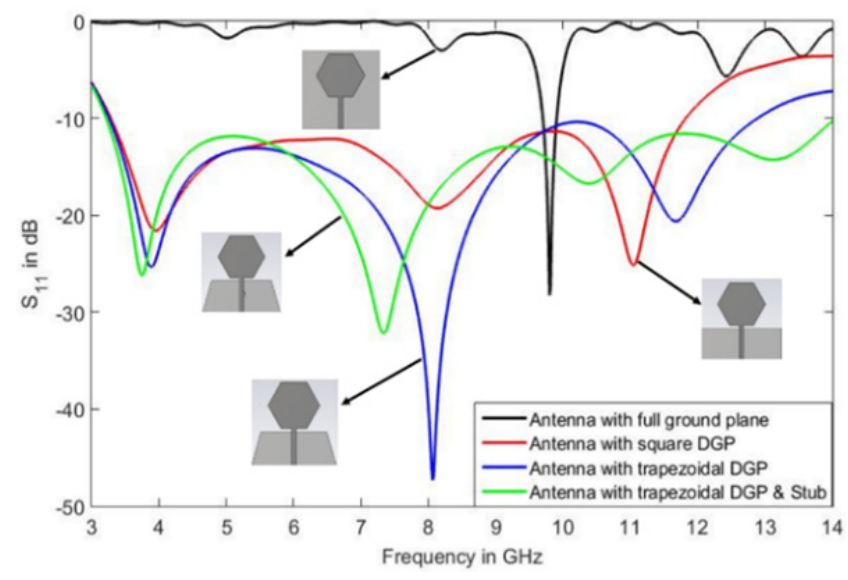

Fig. 2. The $S_{11}$ variations of the antenna with: full ground plane, square DGS, trapezoidal DGS, and joining both trapezoidal DGS with the stub in the feeding line.

ground plane, square defected ground plane (DGP), trapezoidal DGP and by combining the trapezoidal DGP with the stub printed on the feeding line as shown in Fig. 2. One can note, that the antenna version (with full ground) only covers a narrow band at $10 \mathrm{GHz}$, which does not stratify the theme of this work. Thus, in order to enhance the bandwidth, the version of the UWB antenna (with square DGP) was proposed.

This version can operate over the range from $3.3 \mathrm{GHz}$ to $11.75 \mathrm{GHz}$. However, to further improve the antenna bandwidth, the square DGP was modified by trimming 
both edges to form a ground plane with a trapezoidal shape; this increased the bandwidth from $3.1 \mathrm{GHz}$ to $13 \mathrm{GHz}$.

As can be seen in Fig. 2, this has considerable impact on the upper band of UWB spectrum, while it achieved unnoticeable effect on the lower band of the UWB spectrum. To further enhance the antenna bandwidth, the proposed antenna with the trapezoidal DGP shape was fed by a microstrip line with a tuning stub as depicted in Fig. 1(a) "first antenna"; this contributed in increasing the bandwidth by $1 \mathrm{GHz}$. In fact, the UWB antenna (trapezoidal DGP with stub) was able to operate in a very wide frequency range from $3.1 \mathrm{GHz}$ to $14 \mathrm{GHz}$ as demonstrated in Fig. 2.

\section{UWB Antenna with Fixed Rejected Band Characteristics}

In the antenna version of trapezoidal DGP with stub (the first antenna), a wide frequency range from $3.1 \mathrm{GHz}$ to $14 \mathrm{GHz}$ is demonstrated. However, as seen in Fig. 2, the above-mentioned version of the proposed antenna operates over a wide frequency range that may be subject to so cochannel interference; thus a filtering property is required. Firstly, the single stopband function is achieved by etching a half hexagon slot in the radiating patch as shown in Fig. 1(b) (the second antenna). The half hexagon slot has strong coupling with the radiating patch, which helps to reject the upper WLAN band of $5.2 \mathrm{GHz}$ without any alteration in the ultrawide bandwidth characteristic as illustrated in Fig. 3. The dimensions and position of the embedded slot were carefully selected and optimized to meet the first desired rejected band at the higher band of WLAN 5.2 GHz. However, by examining the $\mathrm{S}_{11}$ of the proposed antenna with a single rejected band, it is clear that this antenna also operates from $6 \mathrm{GHz}$ to $10 \mathrm{GHz}$ that may cause interference with some narrow-band systems such as the X-band systems. To reduce the interference with the X-band, an additional rejected band around $10 \mathrm{GHz}$ was engineered by adding another half hexagon slot together with the previous created slot.

This has formed a printed monopole antenna with full hexagon slot (the third antenna) as depicted in Fig. 1(c). One reason that the second notch was created at the X-band is because the radiation element current distribution is changed by etching the full hexagonal slot into the original element. Therefore, the slot stops surface current, which in turn resulted in achieving the stop band. In other word, the current distribution shows the formation of standing waves at this notch frequency. From Fig. 3, one can note that the proposed antenna with full hexagon slot still maintain the same frequency range from $3.1 \mathrm{GHz}$ to $14 \mathrm{GHz}$, while achieving two stop-band features at the WLAN $5.2 \mathrm{GHz}$ and $\mathrm{X}$-band $10 \mathrm{GHz}$.

For validation purposes, three separate prototypes were implemented, the antenna without an embedded slot, with half hexagon slot, and with full hexagon slot; all fabricated on FR4 substrate having relative permittivity of 4.4

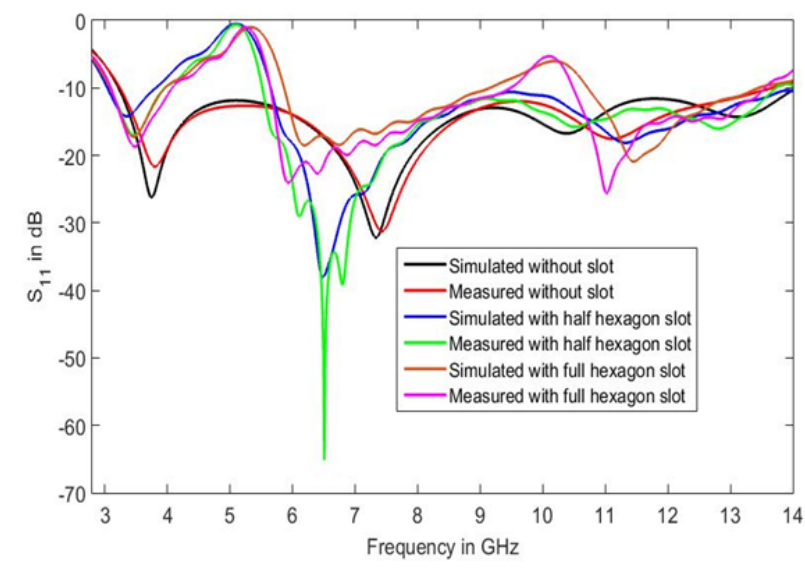

Fig. 3. Simulated and measured $S_{11}$ of the proposed antennas without slot, with half hexagon slot and with full hexagon slot.

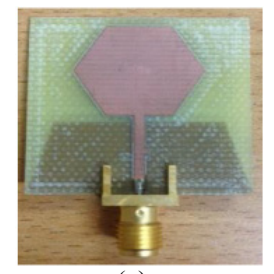

(a)

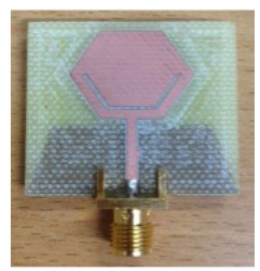

(b)

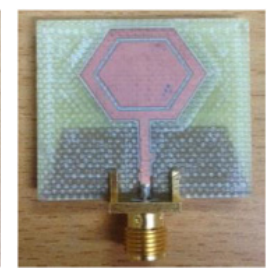

(c)
Fig. 4. The antenna prototypes, (a) without slot, (b) with half hexagon slot, (c) with full hexagon slot.

and thickness of $0.8 \mathrm{~mm}$ as shown in Fig. 4. The reflection coefficients of the three proposed antenna designs were measured by using an Agilent N5230A network analyzer. Figure 3 demonstrates both the measured and simulated $S_{11}$ results versus frequency for the three versions of the antenna.

Comparing the antennas with and without the introduced slot, it can be seen that the fundamental UWB antenna without the inserted slot has an impedance bandwidth from $3.1 \mathrm{GHz}$ to $14 \mathrm{GHz}$, with a reflection coefficient less than $-10 \mathrm{~dB}$, whilst the second version of the proposed antenna with the embedded half hexagon slot still maintains the same impedance bandwidth, but with a filtering notch at WLAN 5.2 GHz. Moreover, the third version also covers the same spectrum, except at WLAN $5.2 \mathrm{GHz}$ and at $\mathrm{X}$-band $10 \mathrm{GHz}$, where the dual rejected bands were produced. This indicates that adding half and full hexagon slots over the radiating patch induces filtering features, while still covering the whole spectrum of UWB. From Fig. 3, it is apparent that the computed outcomes of $\mathrm{S}_{11}$ are in good agreement with the measured data.

In general, the monopole antenna with a small ground plane causes the currents flowing back to the outer surface of the feeding cable, which can result in additional radiation as well as it has an impact on the antenna impedance matching. This may bring a level of differences between the computed and measured radiation patterns and impedance bandwidth of the antenna performances. However, to solve this issue particularly for wideband antenna operation, the feeding cable can be covered with an EMI suppressant material to absorb undesirable EM radiation. By 


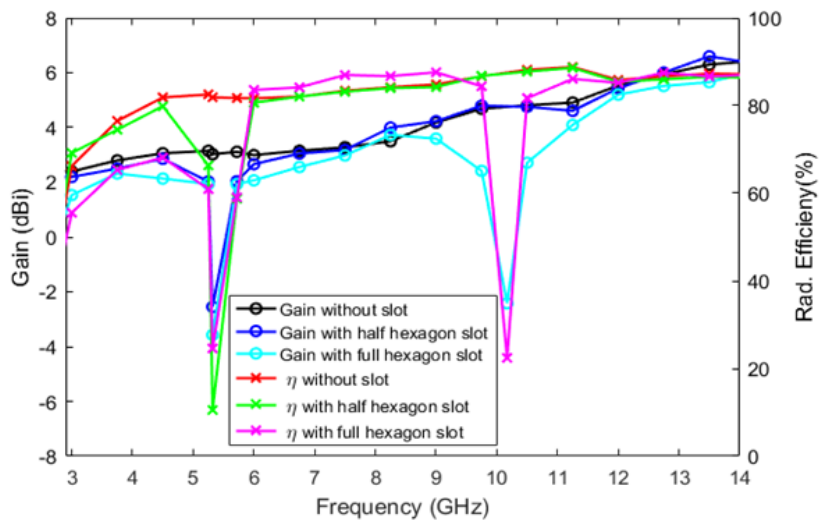

Fig. 5. The gains and radiation efficiencies of the proposed unloaded antennas.

exploiting this approach, the antenna impedance matching in both simulated and measured scenarios of $\mathrm{S}_{11}$ have shown a good agreement as depicted in Fig. 3.

Figure 5 illustrates the gains and radiation efficiencies of the above-mentioned three antennas. The initial antenna design (without slot) exhibits power gain values that vary from $2 \mathrm{dBi}$ up to $6 \mathrm{dBi}$ over the entire spectrum range $(3.1 \mathrm{GHz}$ to $14 \mathrm{GHz})$, whilst the radiation efficiencies range from $78 \%$ at around $3.1 \mathrm{GHz}$ to $83 \%$ at $14 \mathrm{GHz}$. The power gain and efficiencies of the half-hexagonal slot version are also investigated and analyzed in Fig. 5. It clearly shows that the power gain of the proposed antenna with a single notched band demonstrates a gradual improved gain of $2.2 \mathrm{dBi}$ at $3.5 \mathrm{GHz}$ up to around $6 \mathrm{dBi}$ at $14 \mathrm{GHz}$, except at the created notch point of $5.2 \mathrm{GHz}$, where the gain significantly dropped to $-2.2 \mathrm{dBi}$. The radiation efficiencies of this version show a smooth curve at around $83 \%$, except at $5.2 \mathrm{GHz}$, where the efficiency drops to a value of around $12 \%$; as expected the efficiencies are in agreement with the obtained gain. In the case of the third version of the proposed antenna (full hexagonal slot), it shows that the gain increases gradually from $2.1 \mathrm{dBi}$ to more than $5.6 \mathrm{dBi}$ within the passband, with a significant drop of $-3.8 \mathrm{dBi}$ and $-2.4 \mathrm{dBi}$ at the notch frequencies of $5.2 \mathrm{GHz}$ and $10 \mathrm{GHz}$, respectively. The radiation efficiencies are also reduced to around $17 \%$ and $20 \%$ at both rejection bands $(5.2 \mathrm{GHz}$, $10 \mathrm{GHz}$ ), while the antenna achieves a good efficiency in the range from $74 \%$ to $86 \%$ within the passband as indicated in Fig. 5.

\section{UWB Antenna with Tunable Rejected Band Characteristics}

The proposed antennas with half and full hexagon slots (the second and the third designs) have addressed the issue of interference within the UWB spectrum, due to cochannel interference with the WLAN and X-band systems. However, the above-mentioned antenna designs have fixed frequency rejection bands, which are static and will not allow tuning or/and modification of such bands over various ranges, especially when their geometry structures are fabricated.
Thus, one avenue to overcome this issue is to tune/reconfigure the created notches, whilst keeping the frequency range as well as the antennas geometries unchanged/unaltered. A varactor diode was attached at the top of the antenna simulated model with full hexagon slot (the fourth antenna) as depicted in Fig. 1(c). This facilitated the antenna to adaptively tune the notched band to the precise resonant frequency, whenever interference from other systems occur; by varying the capacitance of the attached capacitor, the notched bands will shift accordingly. From Fig. 6, it is clear that by tuning the capacitance of the capacitor from $0.15 \mathrm{pF}$ to $3 \mathrm{pF}$, the lower notched band shifts downwards from $5.1 \mathrm{GHz}$ to $3.2 \mathrm{GHz}$, while the upper rejected band can be swept from $9.9 \mathrm{GHz}$ up to $7.25 \mathrm{GHz}$, but the reflection coefficient in the upper band particularly from $7.25 \mathrm{GHz}$ up to $8.5 \mathrm{GHz}$ is too low, in which this may impair the antenna filtering feature performance.

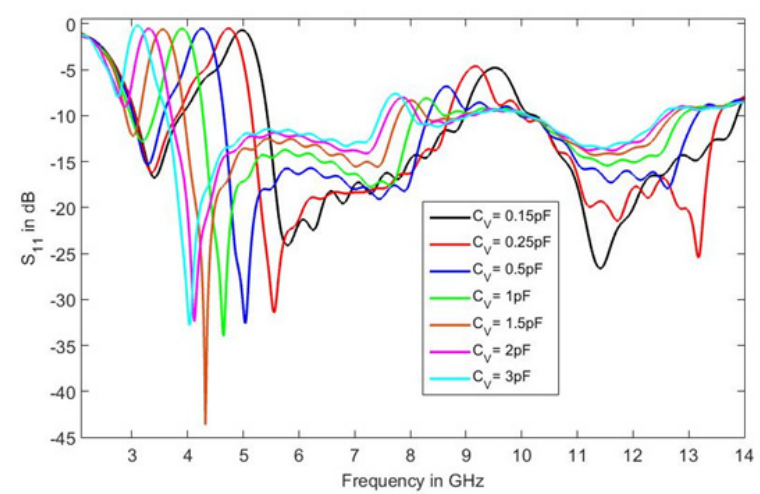

Fig. 6. Simulated $\mathrm{S}_{11}$ of the varactor-loaded antenna.

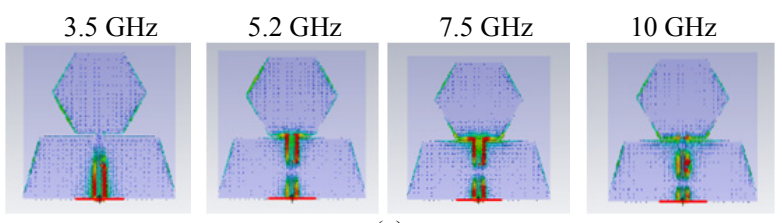

(a)
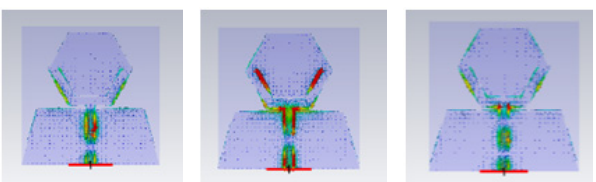

(b)
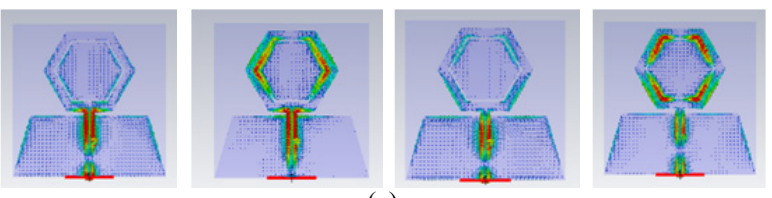

(c)
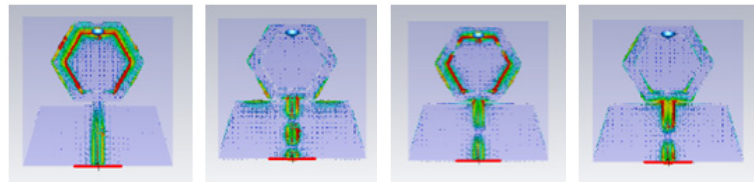

(d)

Fig. 7. The current surfaces for (a) the unslotted antenna, (b) half hexagonal slot antenna, (c) full hexagonal slot antenna, (d) $2 \mathrm{pF}$ loaded antenna; all at $3.5 \mathrm{GHz}$, $5.2 \mathrm{GHz}, 7.5 \mathrm{GHz}$ and $10 \mathrm{GHz}$. 
This wide tuning range will help to avoid interferences with several systems such as the WiMAX system from $3.5 \mathrm{GHz}$ to $3.8 \mathrm{GHz}$, C-band communication satellites from $3.8 \mathrm{GHz}$ to $4.2 \mathrm{GHz}$, and the upper WLAN $5.1 \mathrm{GHz}$ in the case of lower reconfigurable rejected band. While it prevents the interference of X-band, systems from around $10 \mathrm{GHz}$ to $7.5 \mathrm{GHz}$ at the higher notched band.

To further examine the effect of the slots and the varactor, the simulated current distribution of the proposed antennas without slot, with the half hexagon slot, with the full hexagon slot and of the loaded antenna with varactor capacity of $2 \mathrm{pF}$ are indicted in Fig. 7.

The surface current distributions obtained at different frequencies, i.e. $3.5 \mathrm{GHz}, 5.2 \mathrm{GHz}, 7.5 \mathrm{GHz}$ and $10 \mathrm{GHz}$ are shown respectively in Fig. 7(a-d). The current distributions of UWB antenna 1, shown in Fig. 7(a), mainly flow along the microstrip feeding line at the four targeted frequencies since there are no notches However, for the proposed UWB antenna with the half slot as shown in Fig. 7(b), most of the currents appear along the feeding line, except at the frequency of $5.2 \mathrm{GHz}$, in which a strong current flows along the strip line and the half hexagon slot, at the notch band frequency of $5.2 \mathrm{GHz}$; this indicates that the hexagon slot is acting as a resonator. In the case of the third antenna version (full hexagon slot), it can be seen from Fig. 7(c), that the distribution of current is comparatively normal at $3.5 \mathrm{GHz}$ and $7.5 \mathrm{GHz}$. However, the current density of the surface is greatly dense around the full hexagon slot at around $5.2 \mathrm{GHz}$ and $10 \mathrm{GHz}$, where both filtering bands were created.

On other hand, when the third antenna version was loaded with $2 \mathrm{pF}$ as indicated in Fig. 7(d), the current distributions were mainly induced around the feeding strip and the full hexagon slot where the filtering bands were generated, at $3.5 \mathrm{GHz}$ and $7.5 \mathrm{GHz}$. The notch bands at the above-mentioned bands will reduce the EMI for ultra wideband systems, WiMAX and X-band systems.

For proof of concept, the proposed antenna including the varactor and other passive components was fabricated as illustrated in Fig. 8; the packaged BBY52-02W varactor diode offers tuning reverse bias voltage range from $0-15 \mathrm{~V}$. The DC components for controlling the varactor are fitted on the back side of the PCB board, as depicted in Fig. 8.

The DC voltage is isolated from the RF signal using a radiofrequency choke of $100 \mathrm{nH}$ with high $\mathrm{Q}(>40)$, and a tolerance of $65 \%$. The chip inductors feature a monolithic body made of low loss ceramic wound with wire to achieve optimal high frequency performance. A DC-blocking capacitor with value of $100 \mathrm{pF}$ is inserted in the microstrip feed line to prevent DC current flow through. The capacitor used in this measurement are miniature multi-layer ceramic capacitors with high $\mathrm{Q}(>40)$ and ultra-low equivalent series resistance. A $100 \Omega$ resistor was used to control the current flowing to the varactor.

To tune the notched bands of the practical design, the DC bias of the varactor was varied from $0.25 \mathrm{~V}$ and $7.8 \mathrm{~V}$, in which the lower band-notch center frequency would be

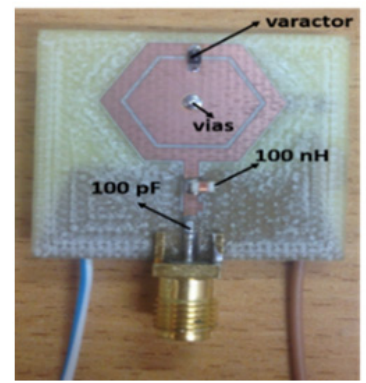

(a)

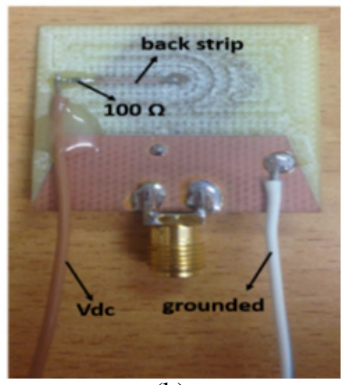

(b)
Fig. 8. The prototype of the antenna with DC bias circuit: (a) top view, (b) back view.

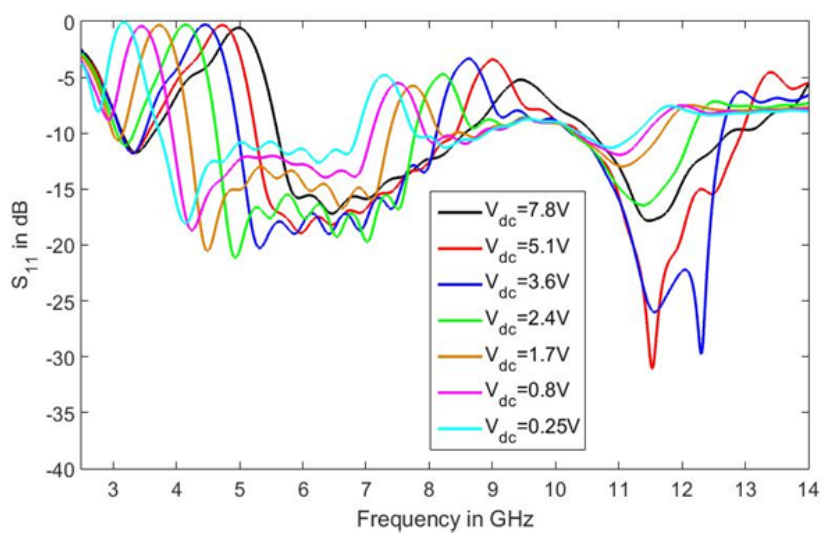

Fig. 9. Measured $S_{11}$ of the varactor-loaded antenna.

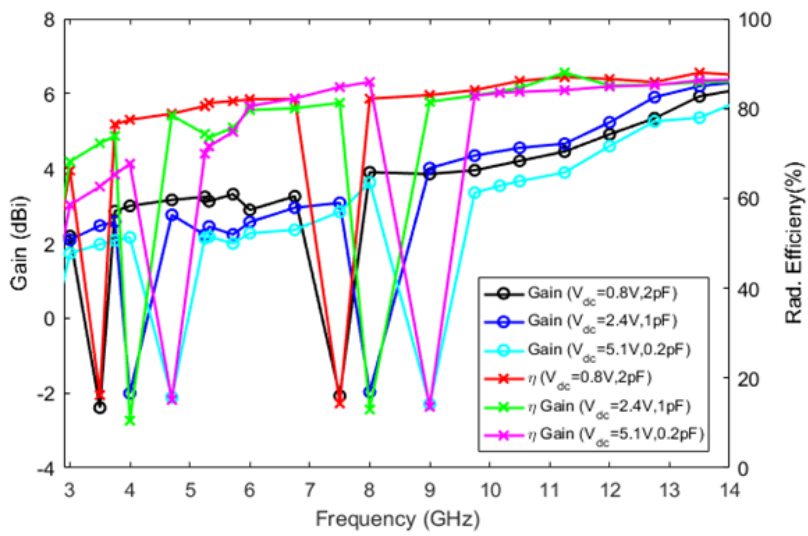

Fig. 10. The measured gains and radiation efficiencies of the loaded varactor antenna.

continuously tuned to reject the bands from $3.2 \mathrm{GHz}$ to $5.1 \mathrm{GHz}$ (with $1.9 \mathrm{GHz}$ obtainable bandwidth), while the upper rejected band can be reconfigured from $7.25 \mathrm{GHz}$ to $9.9 \mathrm{GHz}$ (achieving a tuning bandwidth of $2.5 \mathrm{GHz}$ ), which is sufficient to reject the interference with either the WiMAX (3.5 GHz to $3.8 \mathrm{GHz})$, C-band communication satellites (3.8 to $4.2 \mathrm{GHz}$ ) and/or the lower WLAN (5.15 to $5.35 \mathrm{GHz}$ ).; while at the same time it avoids the interference around the X-band systems (10 GHz up to $7.5 \mathrm{GHz}$ ) at the higher notched band, without affecting the response of the antenna at other frequencies as depicted in Fig. 9. One can note that the simulated findings of $S_{11}$ in Fig. 6 are in good agreement with the measured ones in Fig. 9.

The measured power gains and radiation efficiencies of the varactor-loaded antenna are depicted in Fig. 10. 
Three DC values, namely $0.8 \mathrm{~V}, 2.4 \mathrm{~V}$ and $5.1 \mathrm{~V}$ were selected, which cover the aggregate bandwidth of the UWB frequency band for this study.

From Fig. 10, the loaded antenna with an excitation of $0.8 \mathrm{~V} \mathrm{DC}$ exhibits power gain ranges from $2 \mathrm{dBi}$ to around $5.8 \mathrm{dBi}$, except at both notches of $3.5 \mathrm{GHz}$ and $7.5 \mathrm{GHz}$, where the gain was suppressed to around $-2.5 \mathrm{dBi}$ and $-2.35 \mathrm{dBi}$, respectively. Also, an efficiency from $72 \%$ to $83 \%$ was accomplished when the varactor is excited with $0.8 \mathrm{~V}$, except at the notched bands of $3.5 \mathrm{GHz}$ and $7.5 \mathrm{GHz}$, where the antenna efficiency was reduced to $17 \%$ and $18 \%$, respectively. The peak antenna gain at $2.4 \mathrm{~V} \mathrm{DC}$ is reduced to approximately $-2.1 \mathrm{dBi}$ at the dual notched bands of $4 \mathrm{GHz}$ and $8 \mathrm{GHz}$, while it achieves a smooth gain range from $2 \mathrm{dBi}$ up to $5.9 \mathrm{dBi}$ in the UWB spectrum range. This antenna, with $2.4 \mathrm{~V}$ excitation, demonstrates an efficiency range similar to the case of $0.8 \mathrm{~V}$; however, the antenna efficiency was significantly reduced to $15 \%$ and $17 \%$, respectively at the dual rejected bands of $4 \mathrm{GHz}$ and $8 \mathrm{GHz}$ as depicted in Fig. 10. On the other hand, the proposed loaded antenna indicates that there is an approximate power gain from $1.9 \mathrm{dBi}$ to $4.5 \mathrm{dBi}$ for a $\mathrm{DC}$ of $5.1 \mathrm{~V}$, except at the created rejected bands points $(4.9 \mathrm{GHz}$, $9 \mathrm{GHz}$ ), in which the gain dropped to around $-2.4 \mathrm{dBi}$ and $-2.55 \mathrm{dBi}$, respectively. The efficiency also dropped to $16 \%$ at both points, while it achieved efficiencies from $74 \%$ to $84 \%$ in the UWB spectrum.
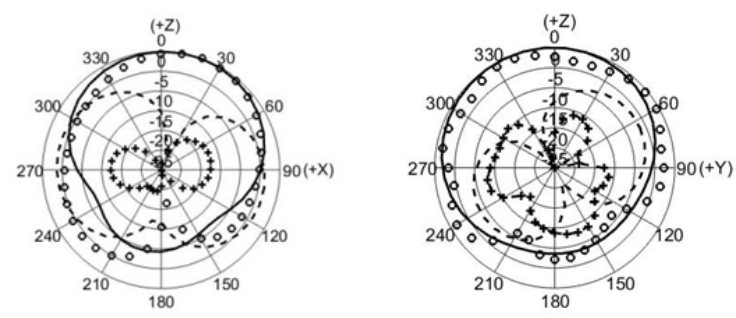

$3.3 \mathrm{GHz}$
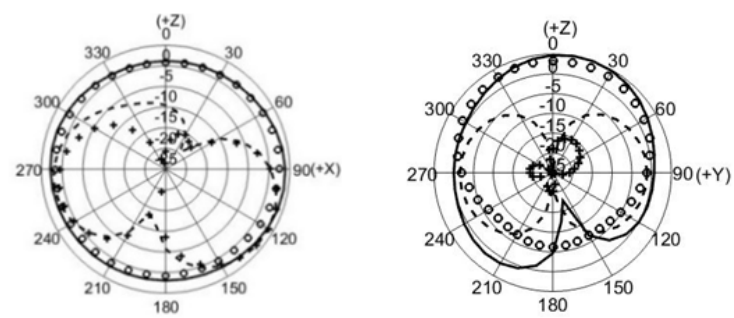

$7 \mathrm{GHz}$
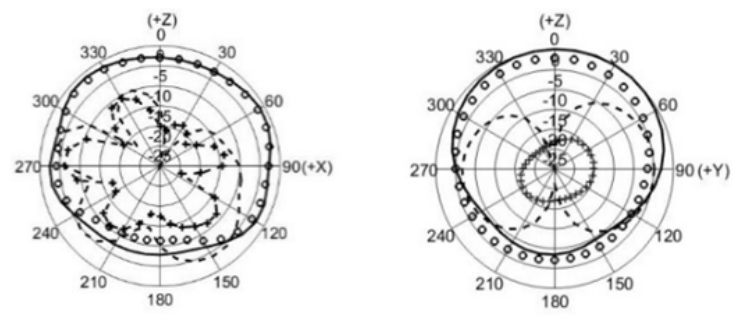

$14 \mathrm{GHz}$

Fig. 11. Simulated against measured normalized antenna radiation patterns for two planes (left: $\mathrm{x}-\mathrm{z}$ plane, right: $\mathrm{y}-\mathrm{z}$ plane) at (a) $3.3 \mathrm{GHz}$, (b) $7 \mathrm{GHz}$, and (c) $14 \mathrm{GHz}$. "ooooo" simulated co-polarization; "++++++" simulated cross-polarization; "___measured copolarization; “--------" measured cross-polarization.
The simulated and measured radiation patterns of the loaded varactor antenna in the E-planes (xz-plane) and $\mathrm{H}$ plane (yz-plane) at 3.3, 7 and $14 \mathrm{GHz}$, which cover the operating bandwidth, were conducted for fabricated varactor-loaded prototype as depicted in Fig. 11. This was carried out when the varactor was excited by $2.4 \mathrm{~V}$, corresponding to equivalent fixed lumped element capacitors of $1 \mathrm{pF}$, respectively. It is noted that the proposed above-mentioned varactor-loaded antenna radiates nearly omnidirectionally in $\mathrm{xz}$ and $\mathrm{yz}$ planes. As mentioned earlier that by using the technique of an EMI suppressant material for absorbing unwanted EM radiation, the shape of the measured and simulated radiation patterns of the antenna will be more or less similar, where neglected/small differences exist in the higher sub-band and relatively noticeable discrepancies in the lower sub-band in particular at $\mathrm{xz}$ plane of 3.3 GHz. This is due to the fact that, the ground plane becomes electrically larger at higher frequencies.

\section{Comparison with Previous Work}

Notable achievements are summarized in Tab. 1 and 2. Standards covered by UWB antennas with fixed single and dual rejected bands features (Tab. 1.) include WiMAX [11-12], upper WLAN [13-14] and X-band [15] for the fixed single notched band. While joining two fixed notched bands within a single antenna design include the WiMAX and upper WLAN in [16-19], both upper bands in WLAN (5.15-5.35 GHz and 5.725-5.875 GHz) in [20] or combining the upper WLAN and X-band as in [21].

\begin{tabular}{|c|c|c|c|c|}
\hline Ref & Size $\left(\mathrm{mm}^{3}\right)$ & $\begin{array}{c}\text { Bandwidth } \\
(\mathrm{GHz})\end{array}$ & $\begin{array}{c}\text { Rejected } \\
\text { bands } \\
(\mathrm{GHz})\end{array}$ & Techniques \\
\hline 11 & $52.25 \times 42 \times 1.57$ & $1.5-15$ & 3.6 & Circular slot \\
\hline 12 & $30 \times 30 \times 1.6$ & $3.1-13.5$ & 3.6 & $\begin{array}{c}\text { Circular split } \\
\text { ring slot }\end{array}$ \\
\hline 13 & $32 \times 52 \times 1.57$ & $3.1-10.6$ & 5.8 & $\begin{array}{c}\text { A mushroom- } \\
\text { structure }\end{array}$ \\
\hline 14 & $28 \times 32.5 \times 1.6$ & $3-10.9$ & 5.8 & $\begin{array}{c}\text { Complementary } \\
\text { Split Ring } \\
\text { Resonator }\end{array}$ \\
\hline 15 & $27 \times 19 \times 1$ & $3.9-14$ & 10.4 & $\begin{array}{c}\text { Dual-T square } \\
\text { resonator }\end{array}$ \\
\hline 16 & $40.0 \times 30.0 \times 1.60$ & $3.1-10.6$ & $3.5 / 5.0$ & $\begin{array}{c}\text { Two U-shaped } \\
\text { slots }\end{array}$ \\
\hline 17 & $46.6 \times 78 \times 1.6$ & $2.63-10.86$ & $3.5 / 5.0$ & $\begin{array}{c}\text { Two L-shaped } \\
\text { slots and two } \\
\text { (SRRs) }\end{array}$ \\
\hline 18 & $35 \times 40 \times 1.62$ & $3.27-10.48$ & $3.3-3.8 /$ & $\begin{array}{c}\lambda_{\mathrm{g}} / 4 \text { resonator } \\
\text { and a C-shaped } \\
\text { slit }\end{array}$ \\
\hline 19 & $40 \times 35 \times 1.6$ & $2.5-12$ & $3.6 / 5.8$ & $\begin{array}{c}\text { CRLH } \\
\text { metamaterial } \\
\text { load }\end{array}$ \\
\hline 20 & $29 \times 40 \times 0.50$ & $3.04-10.56$ & $5.15-5.3 /$ & $\begin{array}{c}\text { Two-pairs of L } \\
\text { resonator and T- } \\
\text { slots }\end{array}$ \\
\hline 21 & $50 \times 50 \times 1.57$ & $3.1-10.6$ & $5.33 / 7.9$ & $\begin{array}{c}\text { Dual-split ring- } \\
\text { resonator (SRR)- } \\
\text { loaded }\end{array}$ \\
\hline proposed & $30 \times 30 \times 0.8$ & $3.1-14$ & $5.2 / 10$ & \begin{tabular}{c} 
Hexagonal slots \\
\hline
\end{tabular} \\
\hline
\end{tabular}

Tab. 1. Comparison of the performance of the published fixed notch UWB antennas. 


\begin{tabular}{|c|c|c|c|c|}
\hline Ref & Size $\left(\mathrm{mm}^{3}\right)$ & $\begin{array}{c}\text { Bandwidth } \\
(\mathrm{GHz})\end{array}$ & $\begin{array}{c}\text { Tunability } \\
\text { Method }\end{array}$ & $\begin{array}{c}\text { Tunable Notched } \\
\text { Frequency Range } \\
(\mathrm{GHz})\end{array}$ \\
\hline 22 & $30 \times 40 \times 0.5$ & $2.8-11.9$ & Varactor & $4.62-5.83$ \\
\hline 23 & $30 \times 39 \times 0.76$ & $2.8-12$ & Varactor & $5.5-9.6$ \\
\hline 24 & $40 \times 40 \times 0.76$ & $3.2-10.5$ & Varactor & $4.77-6.21$ \\
\hline 25 & $24 \times 30 \times 1.52$ & $3.1-10.6$ & Varactor & $5.07-5.83$ \\
\hline 26 & $26 \times 38.1 \times 1.5$ & $2.7-12$ & PINdiode & $3.3-3.7 / 5.15-5.8$ \\
\hline 27 & $26 \times 36.6 \times 1$ & $3.1-10.6$ & $\begin{array}{c}\text { PINdiode/ } \\
\text { Varactor }\end{array}$ & $4.2-4.8 / 5.8-6.5$ \\
\hline 28 & $24 \times 28 \times 1$ & $3.1-11$ & Varactor & $5.1-5.3 / 5.6-5.9$ \\
\hline 29 & $34 \times 27 \times 0.8$ & $3.1-11$ & Varactor & $3.2-4.4 / 5.09-6.6$ \\
\hline proposed & $30 \times 30 \times 0.8$ & $3.1-14$ & Varactor & $3.1-5.1 / 7.25-9.9$ \\
\hline
\end{tabular}

Tab.2. Comparison of the performance of the published tunable notch UWB antennas.

However, to compromise between compact volume, improved bandwidth and agility of notches, some tuning mechanism/approaches were proposed in [22-29] to enable wide tunable rejected band operation, as stated in Tab. 2. The proposed designs have a significant size reduction compared to work in [11-14], [16-24], [26-27], [29], achieved a dual band-suppression with comparison to [11-15], and most importantly the proposed tunable notched band design preserved wider tuning notch range around the $\mathrm{X}$-band $(7.25-10 \mathrm{GHz})$ in contrast with findings in [22-29].

\section{Conclusion}

Compact printed monopole UWB antennas have been presented and experimentally tested. The proposed antenna occupies a compact envelope dimension of $0.31 \lambda_{0} \times$ $0.31 \lambda_{0} \times 0.008 \lambda_{0}$, where $\lambda_{0}$ is the wavelength of the lowest operating frequency. To avoid envisaged co-channel interference within the UWB range, half and full hexagonal slots were inserted at the upper part of the top of the hexagonal radiating patch, in which two rejected bands at the WLAN $5.2 \mathrm{GHz}$ and the $\mathrm{X}$-band range at $10 \mathrm{GHz}$ were accomplished. To tune the fixed notched bands, a varactor diode was utilized to enable electronic tuning; by means of active control of the signal flow, the dual notch-band center frequency could easily be tuned over a wide frequency range from $3.1 \mathrm{GHz}$ to $5.1 \mathrm{GHz}$ and from $7.25 \mathrm{GHz}$ to $9.9 \mathrm{GHz}$. This is in fact the reason of rejecting the bands of WiMAX, WLAN and the X-band downlink satellite system $(7.25-7.75 \mathrm{GHz})$ and other multiple wireless services as close range radar $(8-12 \mathrm{GHz})$ in X-band.

\section{Acknowledgements}

This work is carried out under the grant of the Fundacão para a Ciência e a Tecnologia (FCT - Portugal), with the reference number: SFRH / BPD / 95110 / 2013.

\section{References}

[1] ALLEN, B., DOHLER, M., OKON, E., et al. Ultra Wideband Antennas and Propagation for Communications, Radar and
Imaging. London (UK): Wiley, 2006. ISBN: 9780470032558

[2] FONTANA, R. J. Recent system applications of short-pulse ultrawideband (UWB) technology. IEEE Transactions on Microwave Technology and Technique, 2004, vol. 52, no. 9, p. 2087-2104. DOI: 10.1109/TMTT.2004.834186

[3] FEDERAL COMMUNICATIONS COMMISSION. First Report and order, Revision of part 15 of the Commission's Rule Regarding Ultra-Wideband Transmission System FCC 02-48, 2002.

[4] RAY, K., THAKUR, S., DESHMKH, A. Compact slotted printed monopole UWB antenna. International Journal of Computer Applications in Technology, 2013, p. 16-18. ISSN: 0952-8091

[5] GONG, X., TONG, L., TIAN, Y., GAO, B., Design of a microstrip-fed hexagonal shape UWB antenna with triple notched bands. Progress In Electromagnetics Research C, 2016, vol. 62, p. 77-87. DOI: 10.2528/PIERC15101701

[6] KHAN, M., KHAN, M., AHMAD, I., SALEEM, S. Design of a printed monopole antenna with ridged ground for ultra wideband applications. In Progress In Electromagnetic Research Symposium (PIERS). Shanghai (China), 2016, p. 4394-4396. DOI: 10.1109/PIERS.2016.7735634

[7] AKRAM, S., SHAMBAVI, K., ZACHARIAH, C. Design of printed strip monopole antenna for UWB applications. In IEEE Second International Conference on Electronics and Communication System (ICECS). Coimbatore (India), 2015, p. 823-826. DOI: 10.1109/ECS.2015.7125027

[8] CRUZ, J., FREIRE, R., SERRES, A. Parametric study of printed monopole antenna bioinspired on the Inga Marginata leaves for UWB applications. Journal of Microwaves, Optoelectronics and Electromagnetic Applications, March 2017, vol. 16, p. 312-321. DOI: $10.1590 / 2179-10742017 \mathrm{v} 16 \mathrm{i} 1891$

[9] LI, P., LIANG, J., CHEN, X. Study of printed elliptical/circular slot antennas for ultra wideband applications. IEEE Transactions on Antennas and Propagation, 2006. vol. 54, no. 6, p. 1670-1675. DOI: 10.1109/TAP.2006.875499

[10] ABID, M., KAZIM, J., OWAIS. Ultra-wideband circular printed monopole antenna for cognitive radio applications. International Journal of Microwave and Optical Technology, 2015, vol. 10, no. 3, p. 184-189. ISSN: $1553-0396$

[11] MAHMUD, M., ISLAM, M., SAMSUZZAMAN, M. A compact single notch printed antenna for UWB applications. International Journal of Innovative Research, 2016, vol. 1, no. 1, p. 19-23. ISSN: 2520-5919

[12] YADAV, A., MALAV, A. Microstrip UWB antenna with WiMax notched band characteristics. International Journal of Recent Research and Review, 2014, no. 2, p. 74-77. ISSN: 2277-8322

[13] MANDAL, T., DAS, S. Design of a microstrip fed printed monopole antenna for bluetooth and UWB applications with WLAN notch band characteristics. International Journal of $R F$ and Microwave Computer-Aided Engineering, January 2015, vol. 25 , no. 1, p. 66-74. DOI: $10.1002 /$ mmce. 20824

[14] NAGHaR, A., Alejos, A., FAlCone, F., AghzoUt, O. Synthesis design of single notched-band UWB antenna using the CSRR dynamic resonance. In The 10th European Conference on Antennas and Propagation (EuCAP). Davos (Switzerland), 2016, p. 1-3. DOI: 10.1109/EuCAP.2016.7481932

[15] MIN, X., ZHANG, H., ZHONG, T., CHEN, Q. Design of an UWB antenna with adjustable rejection bandwidth using novel dual-T square resonator. Progress In Electromagnetics Research Letters, 2016, vol. 64, p. 87-92. DOI: 10.2528/PIERL16101501

[16] WAHEED, N., SAADAT, A., UZAIR ZUBAIR, M., et al. Ultrawideband antenna with WLAN and WiMAX band-notch characteristic. In International Conference on Communication, Computing and Digital Systems (C-CODE). Islamabad (Pakistan), 2017, p. 101-105. DOI: 10.1109/C-CODE.2017.7918910 
[17] LIN-CHUAN TSAI A ultrawideband antenna with dual-band band-notch filters. Microwave and Optical Technology Letters, 2017, vol. 59, no. 8, p. 1861-1866. DOI: 10.1002/mop.30639

[18] KIM, S., CHOI, D. Compact filtering monopole patch antenna with dual-band rejection. Springer Plus, June 2016, p. 1-12. DOI: 10.1186/s40064-016-2597-3

[19] MANSOURI, Z., AREZOMAND, A., HEYDARI, S., et al. Dual notch UWB fork monopole antenna with CRLH metamaterial load. Progress In Electromagnetics Research C, 2016, vol. 65, p. 111-119. DOI:10.2528/PIERC16040711

[20] SAM, W., ZAKARIA, Z. Design of a dual-notched ultra-wideband (UWB) planar antenna using L-shaped bandstop resonator. In The 11th European Conference on Antennas and Propagation (EuCAP). Paris (France), 2017, p. 2237-2241. DOI: 10.23919/EuCAP.2017.7928210

[21] SIDDIQUI, J., SAHA, C., ANTAR, Y. Compact dual-SRR-loaded UWB monopole antenna with dual frequency and wideband notch characteristics. IEEE Antennas and Wireless Propagation Letters, 2015, vol. 14, p. 100-103. DOI: 10.1109/LAWP.2014.2356135

[22] HUA, C., LU, Y., LIU, T. UWB heart-shaped planar monopole antenna with a reconfigurable notched band. Progress In Electromagnetics Research Letters, 2017, vol. 65, p. 123-130. DOI: 10.2528/PIERL16120203

[23] SUN1, L., WANG, C., CHEUNG, W., et al. Planar UWB monopole antenna with tunable notch band. In PIERS Proceedings. Kuala Lumpur (Malaysia), 2012, p. 27-30. ISBN: 978-1-934142-20-2

[24] ATAllah, H., ABDEL-RAHMAN, A., YOSHITOMI, K., et al Tunable band-notched CPW-fed UWB monopole antenna using capacitively loaded microstrip resonator for cognitive radio applications. Progress In Electromagnetics Research C, 2016, vol. 62, p. 109-117. DOI: 10.2528/PIERC16010501

[25] MALIK, J., VELALAM, P., KARTIKEYAN, M. Continuously tunable band-notched ultra wide band antenna. Microwave and Optical Technology Letters, 2015, vol. 57, no. 4, p. 924-928. DOI: $10.1002 /$ mop. 28990

[26] GAO, G., HU, B., HE, L., et al. Investigation of a reconfigurable dual notched UWB antenna by conceptual circuit model and timedomain characteristics. Microwave and Optical Technology Letters, 2017, vol. 59, no. 6, p. 1326-1332. DOI: 10.1002/mop.30535

[27] WU, W., LI, Y., WU, R., et al. Band-notched UWB antenna with switchable and tunable performance. International Journal of Antennas and Propagation, 2016, p. 1-6. DOI: $10.1155 / 2016 / 9612987$

[28] TLI, T., ZHU, C., CAO, X., et al. Compact UWB antenna with sharp tunable band-notched characteristics. Microwave and Optical Technology Letters, 2016, vol. 58, no. 3, p. 529-532. DOI: 10.1002/mop.29607

[29] TANG, M., WANG, H., DENG, T., et al. Compact planar ultrawideband antennas with continuously tunable, independent band-notched filters. IEEE Transactions on Antennas and Propagation, 2016. vol. 64, no. 8, p. 3292-3201. DOI: 10.1109/TAP.2016.2570254

[30] CST-COMPUTER SIMULATION TECHNOLOGY AG, 2014.

\section{About the Authors ...}

Issa ELFERGANI received his MSc, and PhD in Electrical and Electronic Engineering from the University of Bradford (UK) in 2008 and 2012, with a specialization in tunable antenna design for mobile handset and UWB applications. He is now a Senior Researcher at the Instituto de
Telecomunicações, Aveiro (Portugal), working with European research funded projects. He is IEEE and American Association for Science and Technology (AASCIT) member. He has published over 80 academic journal and conference papers; in addition, he is the author of two books editorial and eight book chapters. His expertise include research in various antenna designs such as MIMO, UWB, balanced and unbalanced mobile phone antennas, RF MEMS filter technologies and power amplifiers.

Jonathan RODRIGUEZ received his MSc degree in Electronic and Electrical Engineering and Ph.D from the University of Surrey, UK, in 1998 and 2004 respectively. In 2005, he became a researcher at the Instituto de Telecomunicacoes (IT), Portugal. In 2008, he became a Senior Researcher where he established the 4TELL Research Group (http://www.av.it.pt/4TELL/) targeting next generation mobile networks with key interests on green communications, cooperation, and electronic circuit design. He has served as project coordinator for major international research projects that includes Eureka LOOP and FP7 C2POWER, whilst serving as technical manager for FP7 COGEU and FP7 SALUS. Since 2009, he became an Invited Assistant Professor at the University of Aveiro, Portugal, and Associate in 2015. He is author of more than 300 scientific works that includes 6 book editorials. His professional affiliations include: Senior Member of the IEEE and Chartered Engineer (CEng) since 2013, and Fellow of the IET (2015).

Ifiok OTUNG is Professor of Satellite Communications at the University of South Wales. He is author of more than 100 scientific works on the area of mobile and satellite communication systems. In particular, he has led earthspace radio wave propagation research for many years, supervising $16 \mathrm{PhD}$ and over $100 \mathrm{MSc}$ projects and participating in two EPSRC grants (GR/M40356/01, GR/K96601/ 01) as well as KTP (TCS 3661) and ERDF (WEFO 80247) funding and many EU COST programs and collaborative projects with industry. He has also been active in the general area of communication systems where he has authored two textbooks targeted at postgraduate students and researchers, including Digital Communications and Broadband Satellite-Integrated Network Design. His research include: mobile and satellite propagation channels, prediction modelling, and RF design.

Widad MSHWAT awarded MSc degree in Communication and Computer Engineering in 2004, from University Kebangsaan Malaysia. She was appointed as a lecturer, Head of Communication Systems Department at Yafren Higher Institute from 2004 to 2011. Since September 2017, she joined the Faculty of Engineering and Informatics at University of Bradford to pursue her $\mathrm{PhD}$ research degree in the field of Wireless and Mobile Communications Systems and its implementation on 5th Generation networks.

Raed ABD-ALHAMEED received the B.Sc. and M.Sc. degrees from Basrah University, Basrah, Iraq, in 1982 and 1985, respectively, and the Ph.D. degree from the University of Bradford, West Yorkshire, U.K., in 1997, all in 
Electrical Engineering. He is a Professor of electromagnetic and radio frequency engineering at the University of Bradford. His expertise includes in particular the highly realistic analysis of antenna design process in the presence of large multilayer scatterers. He has published over 400 journal and conference papers and is co-author of two books and several book chapters. Dr. Abd-Alhameed is a Fellow of the Institution of Engineering and Technology, Fellow of Higher Education Academy, and a Chartered Engineer in the U.K. 